\title{
Optimal Duration for Clopidogrel Suspension Prior to Coronary Artery Bypass Grafting
}

\author{
Waqas Ullaha, c, Muhammad Arslan Cheema ${ }^{\mathrm{a}}$, Shujaul Haq \\ Hafez Mohammad Abdullah ${ }^{\mathrm{b}}$, Asrar Ahmad ${ }^{\mathrm{a}}$, \\ Marc Cohen ${ }^{\mathrm{a}}$
}

\begin{abstract}
Background: American College of Cardiology (ACC) guidelines suggest clopidogrel (Plavix) suspension for 5 days before non-emergent cardiac surgery (class IIa, level B). It puts the patients with recent angioplasty and ongoing ischemia at a higher risk of stent thrombosis. We sought to determine the bleeding risk in patients who stopped clopidogrel at 3 and less than 3 days before coronary artery bypass grafting $(\mathrm{CABG})$ as compared to the usual 5 days prior to $\mathrm{CABG}$.
\end{abstract}

Methods: A retrospective single center study was performed; and a total of 90 patients were included. Forty patients were not on clopidogrel but underwent $\mathrm{CABG}$ and hence were used as a control group (group 3). Fifty remaining patients were divided into three groups. Patients in whom clopidogrel was stopped 3 days or less before CABG were included in group $1(\mathrm{n}=25)$; group 2 included patients who followed the standard ACC guidelines and clopidogrel was suspended 5 days before the CABG $(\mathrm{n}=17)$; and finally patients who had stopped clopidogrel 4 days prior to surgery were included in group $4(n=8)$. This was compared to controls. Postoperative hemoglobin drop was analyzed between subgroups using IBM SPSS version 25 .

Results: The mean age of the included population was 69.9 years (46 - 88) with $65 \%$ of them being male and $35 \%$ female patients. The difference in the hemoglobin fall was compared amongst these groups using the one-way ANOVA. There were no outliers, as assessed by boxplot, the data were normally distributed for each group, as assessed by Shapiro-Wilk test $(\mathrm{P}>0.05)$, and there was homogeneity of variances, as assessed by Levene's test of homogeneity of variances $(\mathrm{P}>0.05)$. The fall in hemoglobin for the four different groups was analyzed. The fall in hemoglobin in group 1 (stopped clopidogrel 3 days or less before $\mathrm{CABG})$ was $(\mathrm{n}=25,2.36 \pm 1.24)$, the fall in group 2 (stopped clopidogrel 5 days prior to $\mathrm{CABG}$ ) was $(\mathrm{n}=17,2.89 \pm$ 1.22), the fall in hemoglobin in group 3 (patients not on clopidogrel ) was $(n=40,2.54 \pm 1.35)$, and the fall in hemoglobin in group 4

Manuscript submitted February 9, 2019, accepted March 29, 2019

aAbington-Jefferson Health, 1200 Old York Road, Abington, PA 19001, USA bUniversity of South Dakota Sanford School of Medicine, Sioux Falls, SD, USA

${ }^{\mathrm{c} C}$ Corresponding Author: Waqas Ullah, Abington-Jefferson Health, 1200 Old York Road, Abington, PA 19001, USA. Email: waqasullah.dr@gmail.com

doi: https://doi.org/10.14740/cr842 (patients stopped clopidogrel 4 days prior to $\mathrm{CABG}$ ) was ( $\mathrm{n}=8,2.02$ \pm 1.31 ). ANOVA was subsequently performed on the patient data, which showed no statistical difference between all the four groups regarding the fall in hemoglobin during surgery $(\mathrm{P}=0.41)$.

Conclusions: Our study concludes that there was no significant difference in the hemoglobin drop of the patients who had clopidogrel stopped 3 days prior to the major procedure like CABG in comparison to the patients who stopped clopidogrel 5 days before surgery. We advocate, that early cessation of clopidogrel is posing a threat of thrombosis in high risk patients with no additional benefit of decreased bleeding risks. However, large population studies are needed to validate the results.

Keywords: Clopidogrel; CABG; Bleeding risk

\section{Introduction}

Clopidogrel is an irreversible platelet aggregation inhibitor prescribed to improve outcomes of ischemic cardiomyopathy especially by reducing early coronary artery stent failure $[1,2]$. As platelets lack the ability for protein synthesis, aggregation can only be restored by de novo synthesis of platelets. Since the half-life of platelet is approximately 8 - 10 days, it requires about 5 days for the replenishment of platelet pool [3]. This unmasks the downside of clopidogrel administration prior to major procedures and puts surgical patients at higher risk of postoperative bleeding. Hence, bleeding necessitating blood transfusions or severe postoperative anemia is a devastating complication after major procedures like cardiac surgery especially coronary artery bypass graft (CABG) [4].

To find the balance between the two catastrophic complications of post stenting thrombosis and post $\mathrm{CABG}$ bleeding, it is important to consider if and when the preoperative clopidogrel should be terminated [3]. However, there is no convincing data on the preoperative optimal timing of clopidogrel discontinuing prompting us to investigate this study.

\section{Materials and Methods}

The 90 post CABG patients involved in this study were randomly selected by retrospective chart review at the Abington Hos- 


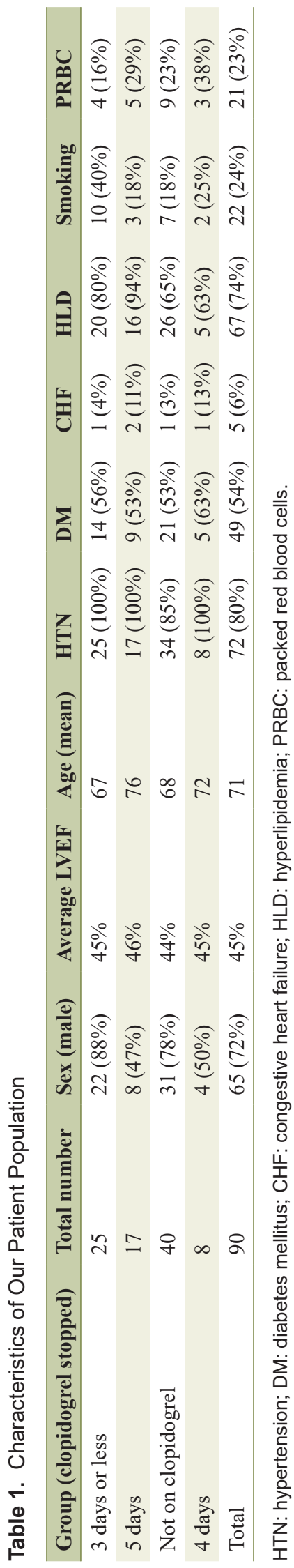

pital-Jefferson Health, PA. Institutional Review Board (IRB) and ethics committee approved the study (FWA0004123). It was a retrospective study in compliance with hospital ethics committee protocol and had no actual human or animals subjects. Since, there was no direct patient interaction so the patient right to consent was waived by the IRB.

The included population had their bypass surgery done as per our institutional protocol where cell saver was used on all patients. All the patients were randomly assigned and matched into two main arms, study arm and a control arm that had similar baseline characteristics as the study arm but was not using clopidogrel. The study arm was further classified into three groups based on the day of termination of clopidogrel before CABG. The first group contained patients who discontinued clopidogrel 3 days or less prior to CABG procedure and the second group recruited patients who had clopidogrel terminated 5 days before $\mathrm{CABG}$.

All patients using preoperative anticoagulants, having bleeding disorder or unknown clopidogrel discontinuation date were excluded from the study. Similarly, patients who had pre or post procedural platelet or fresh frozen plasma transfusions and left ventricular ejection fraction (LVEF) less than $40 \%$ were excluded. Only patients with isolated packed red blood cell (PRBC) transfusions were included in the study. Similarly, patients who were not using aspirin due to any reason like allergy or intolerance were excluded from the study. All included patients were on equal dose of aspirin $81 \mathrm{mg}$. The primary endpoint was a fall in the hemoglobin levels post surgery or patients requiring a PRBC transfusions post surgery. None of our patients had any major adverse cardiac events (MACE); and this could not be studied. Analysis was done using the SPSS software version 25 .

\section{Results}

Our study population consisted of 90 patients who underwent CABG. Fifty (56\%) of these patients were on clopidogrel, while $40(44 \%)$ patients were not on clopidogrel, and were used as controls. The mean age for our study sample was 69.4 years $(46-88)$. The number of males in our study was 65 (72.3\%), and the number of females was $25(27.7 \%)$. We could not randomize the groups as it was a retrospective study, but the patients in all groups were best matched based on their age, gender and comorbidities (Table 1). Overall, 84 (93\%) patients had hypertension, 49 (54\%) patients had diabetes mellitus, 67 (74\%) had dyslipidemia, 22 (24\%) had a history of smoking and five $(6 \%)$ had a history of heart failure. The total number of patients who got PRBC transfusion was 21 , with nine patients in control group and 12 patients in study group. The average LVEF for all groups was around $45 \%$ (Table 1). All CABG surgeries in both groups were performed with pump and had on average two bypasses; the types of conduits used were left internal mammary artery (LIMA) and saphenous vein (SV).

The cases were further subdivided into groups and analyzed. A one-way ANOVA was conducted to determine if the timing of clopidogrel cessation was a risk factor for excessive bleeding and resultant fall in hemoglobin. This was compared with patients who were not on clopidogrel. Participants were 
Table 2. Patient Population Divided Into Four Groups

\begin{tabular}{lllll} 
& Frequency & Percent & Valid percent & Cumulative percent \\
\hline Clopidogrel stopped 3 days or less & 25 & 27.8 & 27.8 & 27.8 \\
Clopidogrel stopped 5 days & 17 & 18.9 & 18.9 & 46.7 \\
Not on clopidogrel & 40 & 44.4 & 44.4 & 91.1 \\
Clopidogrel stopped 4 days before & 8 & 8.9 & 8.9 & 100.0 \\
Total & 90 & 100.0 & 100.0 & \\
\hline
\end{tabular}

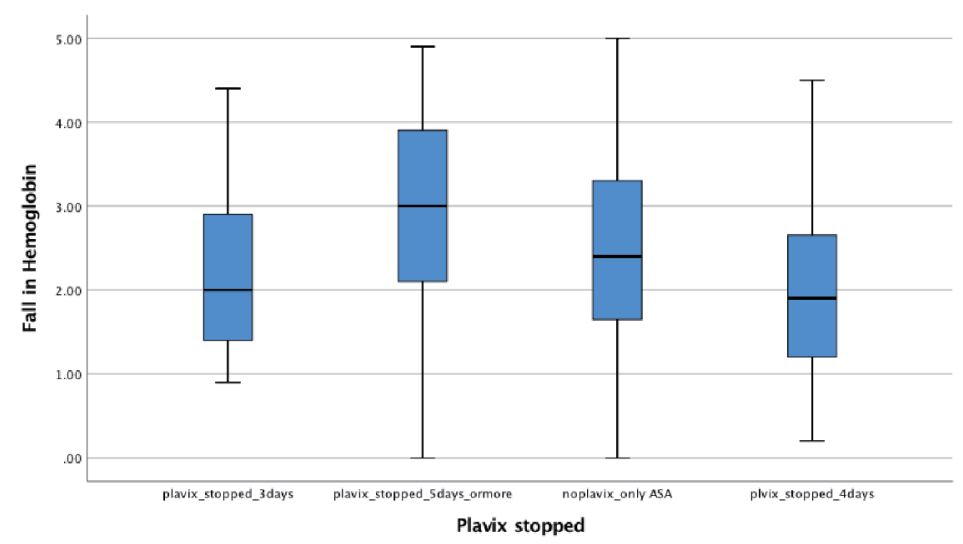

Figure 1. Test of variance. There were no outliers in the data, as assessed by inspection of a boxplot for values greater than 1.5 box-lengths from the edge of the box.

classified into four groups: patients in whom clopidogrel was stopped 3 days or less before CABG were included in group $1(\mathrm{n}=25)$; patients in whom clopidogrel was stopped 5 days before surgery were included in group $2(n=17)$; control patients who were not on clopidogrel but underwent CABG were included in group $3(\mathrm{n}=40)$; and finally patients who had stopped clopidogrel 4 days prior to surgery were included in group $4(n=8)$. This is presented in Table 2. The difference in the hemoglobin fall was compared amongst these groups using the one-way ANOVA. There were no outliers, as assessed by boxplot (Fig. 1). The data were normally distributed for each group, as assessed by Shapiro-Wilk test $(\mathrm{P}>0.05)$ (Table 3$)$. There was homogeneity of variances, as assessed by Levene's test of homogeneity of variances $(\mathrm{P}>0.05)$ (Table 4$)$. The data

Table 3. Test of Normality

\begin{tabular}{|c|c|c|c|c|c|c|}
\hline \multirow{2}{*}{ Clopidogrel stopped } & \multicolumn{3}{|c|}{ Kolmogorov-Smirnov } & \multicolumn{3}{|c|}{ Shapiro-Wilk } \\
\hline & Statistic & df & Sig. & Statistic & df & Sig. \\
\hline Clopidogrel stopped 3 days & 0.188 & 25 & 0.02 & 0.885 & 25 & 0.09 \\
\hline No clopidogrel & 0.066 & 40 & 0.20 & 0.973 & 40 & 0.435 \\
\hline Clopidogrel stopped 4 days & 0.178 & 8 & 0.20 & 0.962 & 8 & 0.832 \\
\hline
\end{tabular}

The fall in hemoglobin was normally distributed for all the groups, as assessed by Shapiro-Wilk's test $(P>0.05)$

Table 4. Test of Homogeneity of Variances for Hemoglobin Drop

\begin{tabular}{lllll}
\hline & Levene statistic & df1 & df2 & Sig. \\
\hline Based on mean & 0.214 & 3 & 86 & 0.886 \\
Based on median & 0.314 & 3 & 86 & 0.815 \\
Based on median and with adjusted df & 0.314 & 3 & 84.115 & 0.815 \\
Based on trimmed mean & 0.268 & 3 & 86 & 0.848 \\
\hline
\end{tabular}

There was homogeneity of variances, as assessed by Levene's test for equality of variances $(P>0.05)$. 
Table 5. Fall in Hemoglobin for the Four Different Groups

\begin{tabular}{lllllll} 
& N & Mean & Std. deviation & Std. error & \multicolumn{2}{c}{ 95\% Confidence interval for mean } \\
& & & & & Lower bound & Upper bound \\
\hline Clopidogrel stopped 3 days or less & 25 & 2.3560 & 1.23628 & 0.24726 & 1.8457 & 2.8663 \\
Clopidogrel stopped 5 days & 17 & 2.8824 & 1.22384 & 0.29683 & 2.2531 & 3.5116 \\
Not on clopidogrel & 40 & 2.5400 & 1.34904 & 0.21330 & 2.1086 & 2.9714 \\
Clopidogrel stopped 4 days ago & 8 & 2.0250 & 1.30903 & 0.46281 & 0.9306 & 3.1194 \\
Total & 90 & 2.5078 & 1.29165 & 0.13615 & 2.2372 & 2.7783 \\
\hline
\end{tabular}

Data are presented as mean \pm standard deviation. The fall in hemoglobin $(\mathrm{g} / \mathrm{dL})$ in group 1 (stopped clopidogrel 3 days or less before CABG) was $2.36 \pm 1.24(n=25)$; the fall in group 2 (stopped clopidogrel 5 days prior to CABG) was $2.89 \pm 1.22(n=17)$; the fall in hemoglobin in group 3 (patients not on clopidogrel) was $2.54 \pm 1.35(n=40)$; and the fall in hemoglobin in group 4 (patients stopped clopidogrel 4 days prior to CABG) was $2.02 \pm$ $1.31(n=8)$.

is presented as mean \pm standard deviation in Table 5 and Figure 2. The fall in hemoglobin for the four different groups is presented in Table 5. The fall in hemoglobin in group 1 (stopped clopidogrel 3 days or less before $\mathrm{CABG})$ was $(\mathrm{n}=25,2.36 \pm$ 1.24 ); the fall in group 2 (stopped clopidogrel 5 days prior to CABG) was $(n=17,2.89 \pm 1.22)$; the fall in hemoglobin in group 3 (patients not on clopidogrel) was $(n=40,2.54 \pm 1.35)$; and the fall in hemoglobin in group 4 (patients stopped clopidogrel 4 days prior to $\mathrm{CABG})$ was $(\mathrm{n}=8,2.02 \pm 1.31)$. This is also shown in Figures 2 and 3. ANOVA was subsequently performed on the patient data. It showed that there were no statistically significant differences in fall in hemoglobin in all the different groups $(\mathrm{F}(3,86)=0.972, \mathrm{P}=0.410)$, with post hoc analysis showing a partial eta squared value $=0.033$ (Table 6) There was no statistically significant difference between any groups when compared to the other groups regarding the fall in hemoglobin during the surgery. This is demonstrated in the table for multiple outcomes (Table 7).

Furthermore, Figure 4 also demonstrated the difference in the requirement for PRBC transfusions in all the groups post CABG. The institutional protocol followed for PRBC transfusion was all patients having any one of the following, active bleeding, hemoglobin $<7 \mathrm{~g} / \mathrm{dL}$, or symptomatic anemia. The cumulative percent of patients requiring transfusions was
$23 \%$. Out of all the patients who were taking clopidogrel, 12 of them required blood transfusion, which is $24 \%$ of the patients. On the other hand, nine patients who were not on clopidogrel also required a blood transfusion, which is $22.5 \%$ of these patients. There was no significant difference in PRBC transfusion amongst the patients who were on clopidogrel as compared to those who were not on clopidogrel.

\section{Discussion}

CABG surgery has been shown to be superior to percutaneous coronary intervention (PCI) in multivessel coronary artery disease. This is reinforced by the latest literature by the American College of Cardiology (ACC). CABG is also preferred when there is complex coronary anatomy, and history of diabetes [5]. However, in contrast to PCI, CABG is a major surgical procedure and puts the patients at higher risk of bleeding, especially those with a bleeding disorder or on antiplatelet medications like clopidogrel. Clopidogrel use prior to CABG procedure is thought to be associated with a high risk of post-CABG bleeding and increased transfusion requirements [5]. On the other hand clopidogrel discontinuation may put cardiac patients at increased risk of an ischemic insult. As of now, there is no

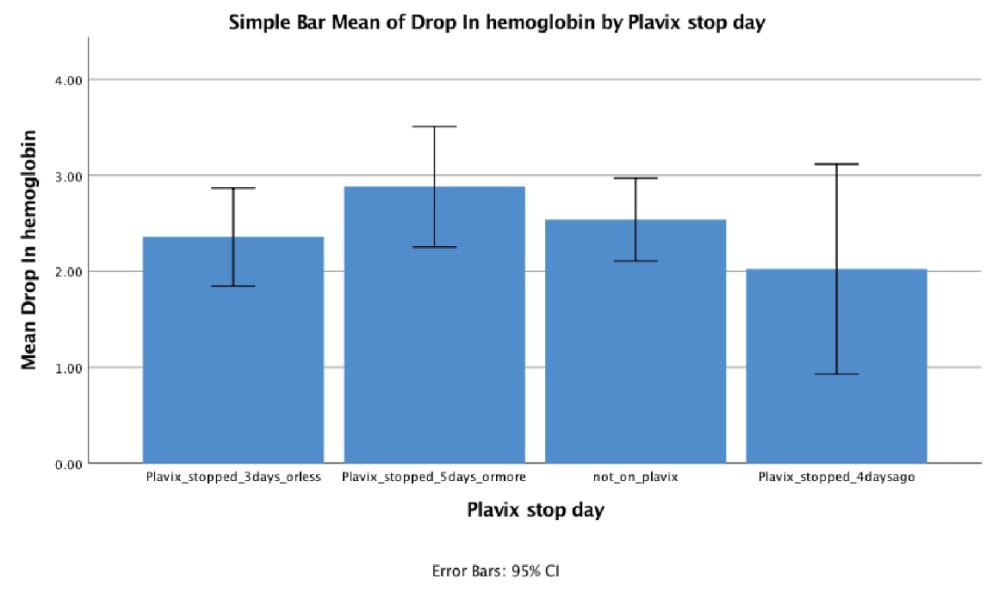

Figure 2. Bar chart of the four groups, describing the mean and standard error 


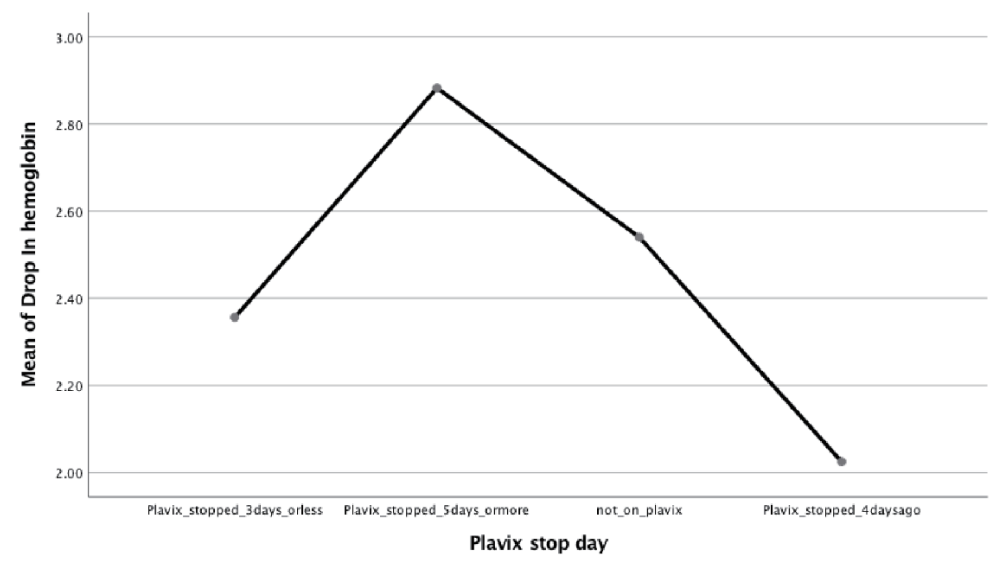

Figure 3. Graph demonstrating mean fall in hemoglobin in the different groups.

concrete evidence available to determine the period of discontinuation of clopidogrel and the timing of the CABG procedure. The 2011 ACCF/AHA Class-I recommendation states that clopidogrel should be withdrawn 5 days prior to $\mathrm{CABG}$ [6]. However, there has been conflicting data about these recommendations. As the CURE trial demonstrated, that there is no statistical difference in bleeding between placebo and clopi- dogrel groups in whom medication was discontinued $\geq 5$ days before surgery [2].

Current ACC guidelines recommend that clopidogrel therapy should be held at least 5 days before elective $\mathrm{CABG}$ procedure due to a higher risk of bleeding, high re-operative rates, slower post-operative recovery and increased red blood cell transfusions [7-9]. Other studies have shown no benefits

Table 6. Fall in Hemoglobin on ANOVA in All the Different Groups

\begin{tabular}{llllll} 
& Sum of squares & df & Mean square & F & Sig. \\
\hline Between groups & 4.867 & 3 & 1.622 & 0.972 & 0.410 \\
Within groups & 143.617 & 86 & 1.670 & & \\
Total & 148.485 & 89 & & & \\
\hline
\end{tabular}

There were no statistically significant differences in fall in hemoglobin on ANOVA in all the different groups. $F(3,86)=0.972, P=0.410$.

Table 7. Fall in Hemoglobin During the Surgery Between Any Group When Compared to the Other Groups

\begin{tabular}{|c|c|c|c|c|c|}
\hline \multirow{2}{*}{ (J) Clopidogrel stop day } & \multirow{2}{*}{ Mean difference (I-J) } & \multirow{2}{*}{ Std. error } & \multirow{2}{*}{ Sig. } & \multicolumn{2}{|c|}{ 95\% Confidence interval } \\
\hline & & & & Lower bound & Upper bound \\
\hline Clopidogrel stopped 5days ${ }^{\mathrm{a}}$ & -0.52635 & 0.40624 & 0.568 & -1.5907 & 0.5380 \\
\hline Clopidogrel stopped 4 days ago ${ }^{a}$ & 0.33100 & 0.52492 & 0.922 & -1.0443 & 1.7063 \\
\hline Clopidogrel stopped 3 days or less ${ }^{b}$ & 0.52635 & 0.40624 & 0.568 & -0.5380 & 1.5907 \\
\hline Clopidogrel stopped 3 days or less ${ }^{c}$ & 0.18400 & 0.32947 & 0.944 & -0.6792 & 1.0472 \\
\hline Clopidogrel stopped 5 days ${ }^{\mathrm{c}}$ & -0.34235 & 0.37414 & 0.797 & -1.3226 & 0.6379 \\
\hline Clopidogrel stopped 4 days ago ${ }^{c}$ & 0.51500 & 0.50050 & 0.733 & -0.7963 & 1.8263 \\
\hline Clopidogrel stopped 3 days or less ${ }^{\mathrm{d}}$ & -0.33100 & 0.52492 & 0.922 & -1.7063 & 1.0443 \\
\hline
\end{tabular}

There was no statistically significant difference between any groups when compared to the other groups regarding the fall in hemoglobin during the surgery. This is demonstrated in the table for multiple outcomes ( ${ }^{\mathrm{a} C o m p a r i s o n}$ with group $1 ;$; ${ }^{b}$ Comparison with group 2 ; ' $\mathrm{C}$ Comparison with group 3 ; ${ }^{\mathrm{d} C o m p a r i s o n}$ with group 4). 


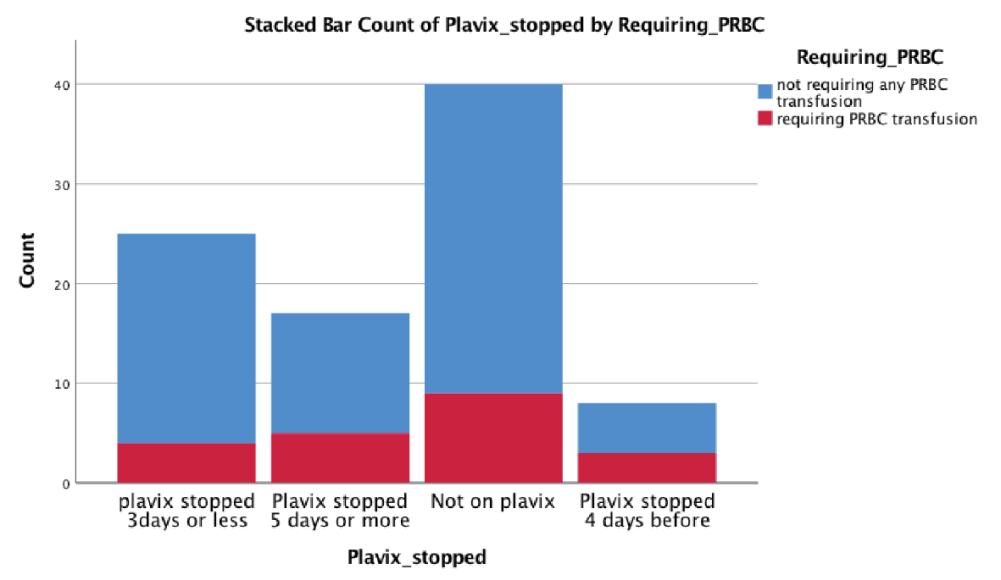

Figure 4. Showing the frequency of packed red blood cell transfusions in these groups.

of preoperative clopidogrel termination 5 days prior to $\mathrm{CABG}$ and stated that patients are at high risk of thrombosis [10]. In a study with patients undergoing CABG after acute coronary syndrome, the group that was given pre-operative clopidogrel showed a lesser incidence of stroke, myocardial infarction (MI), cardiovascular death as compared to the placebo [11]. To assess this recommendation we aimed to study post CABG patients who were on clopidogrel and study if the timing of clopidogrel cessation had any adverse outcomes. To eliminate the confounding factors, all patients with any type of bleeding disorder were excluded from the study. Similarly, all the patients included were taking aspirin too. This approach enabled us to attribute the post-procedure bleeding to clopidogrel use. We also excluded all patients on oral anticoagulants.
Further the two groups were matched by comparing the baseline characteristics and underlying comorbidities of the patients as they contribute significantly towards the incidence of cardiovascular disease. As shown by the INTERHEART study, these risk factors contribute significantly towards cardiovascular disease (CVD) and subsequent MI [12]. Different cardiovascular risk factors have a joint effect and in turn, increase the likelihood of developing coronary disease [1]. Hypertension has been linked to the development of heart failure [1], left ventricular hypertrophy [13] and also coronary artery disease [14] which can be considered its most serious consequence. It is complicated by the fact hypertension occurs concurrently with other conditions which increase cardiovascular mortality such as dyslipidemia and obesity [14]. Overall, in our study sample,

Table 8. Pre- and Post-CABG Hemoglobin Levels and the Mean Change in Hemoglobin

\begin{tabular}{llll} 
& Pre-operative & Post-operative & Delta \\
\hline Overall & 12.5 & 9.8 & -2.4 \\
Cases & 11.8 & 9.3 & -2.5 \\
Controls & 12.8 & 10.3 & -2.5 \\
\hline
\end{tabular}

Table 9. Difference of Mean Hemoglobin Drop With Respect to the Duration of Clopidogrel Termination Prior to CABG

\begin{tabular}{ll}
\hline Study group & Fall in hemoglobin $(\mathbf{g} / \mathbf{d L})$ \\
\hline Clopidogrel stopped 3 days or less before surgery & $\mathrm{n}=25,2.36 \pm 1.24$ \\
Clopidogrel stopped 5 days before surgery & $\mathrm{n}=17,2.89 \pm 1.22$ \\
Clopidogrel stopped 4 days before surgery & $\mathrm{n}=8,2.02 \pm 1.31$ \\
No clopidogrel & $\mathrm{n}=40,2.54 \pm 1.35$ \\
\hline
\end{tabular}

Table10. Number of Patients Requiring PRBC Transfusions in the Different Population Group

\begin{tabular}{llll} 
Patient group & Total number of patients & Number requiring PRBC transfusion & Percentage requiring PRBC transfusion \\
\hline Cases & $\mathrm{n}=50$ & $\mathrm{n}=12$ & $24.00 \%$ \\
Controls & $\mathrm{n}=40$ & $\mathrm{n}=9$ & $22.50 \%$ \\
Total & $\mathrm{n}=90$ & $\mathrm{n}=21$ & $23.33 \%$ \\
\hline
\end{tabular}


$84(93.3 \%)$ patients had hypertension. About $33(84.6 \%)$ of the control group and $50(100 \%)$ of the study group had a history of hypertension. Similarly, diabetes adds to the already menacing process of atherosclerosis as it increases coagulability and platelet adhesion while simultaneously impairing fibrinolysis. This has been shown to increase the incidence of vascular events and cardiovascular disease associated with mortality [15-17]. Interestingly, patients with diabetes are considered to have the same risk as someone with pre-existing coronary artery disease as per ADA guidelines [10]. This fact stems from studies demonstrating that the risk of development of $\mathrm{MI}$ in diabetics is equivalent to non diabetics with a history of prior MI [18]. We looked at the prevalence of diabetes mellitus (DM) in our study population. In the overall sample, $49(54.4 \%)$ of patients had DM. In the cases and control groups, the incidence of DM was 29 $(56.9 \%)$ and $20(51.3 \%)$ respectively. Hyperlipidemia is also a well-known risk factor for cardiovascular disease [19-20]. The prevalence of hyperlipidemia was examined in our overall sample and it was found out to be $67(74.4 \%)$ and $42(82.4 \%)$ cases in the study group, and $25(64.1 \%)$ cases in the control group. Smoking has been proven to increase the incidence of CVD and MIs [12]. The overall incidence of smoking in our study population was $22(24.4 \%)$. A further breakdown of the data showed that $15(29.4 \%)$ of the cases had a history of smoking while in the control group only seven $(17.9 \%)$ of people had a smoking history. Moreover, greater than $60 \%$ of congestive heart failure (CHF) in the general US population can be attributed to CAD [16-20]. In our study, five (5.6\%) of our study population had a history of CHF. In the cases group, four (7.8\%) of the patients had $\mathrm{CHF}$, while in the control group one of the patients with CHF (2.6\%).

The primary endpoints that we used in our study were a decrease in hemoglobin post surgery and also the number of red blood cell transfusions required. This was thought to be a good predictor of excessive intra or postoperative bleeding. In our study, the preoperative hemoglobin $(\mathrm{g} / \mathrm{dL})$ in all population ranged from 8.1 - 16.4 with an average of 12.2. In the study group, the hemoglobin ranged from $8.9-15.4$ with an average of $11.8 \mathrm{~g} / \mathrm{dL}$, while in the control group, the hemoglobin ranged from $8.1-16.4$ with an average of $12.8 \mathrm{~g} /$ dL. Subsequently, the hemoglobin levels of the patients were tracked on postoperative day 1 . In the total population, the hemoglobin ranged from $6.6-15.8$ with an average of $9.8 \mathrm{~g} /$ $\mathrm{dL}$. The hemoglobin of the study group ranged from $6.6-12.9$ with an average of $9.3 \mathrm{~g} / \mathrm{dL}$, while that in the control group ranged from 7.0 - 15.8 with an average of $10.3 \mathrm{~g} / \mathrm{dL}$. It is interesting to note that the average drop in hemoglobin between the two groups was not significantly different from each other (Table 8).

We further analyzed the outcomes in the 50 patients who were on clopidogrel. We did this by stratifying them into groups based on when the clopidogrel was stopped. The first group consisted of patients in whom clopidogrel was stopped 3 days or less before surgery; while 25 patients made up $50.0 \%$ of the cases group. Pre-operative hemoglobin ranged from 9 $15.4 \mathrm{~g} / \mathrm{dL}$ while post-operative hemoglobin ranged from 6.6 - $12.2 \mathrm{~g} / \mathrm{dL}$. This group demonstrated a mean hemoglobin drop of $2.36 \mathrm{~g} / \mathrm{dL}$. Similarly, we looked at the pre and post-operative hemoglobin levels of the patients in whom clopidogrel was stopped 5 days before the surgery; while 19 patients made up $33.3 \%$ of the cases. Pre-operative hemoglobin ranged from $8.9-15.0 \mathrm{~g} / \mathrm{dL}$. The post-operative hemoglobin ranged from $6.6-12.9 \mathrm{~g} / \mathrm{dL}$. This group showed a mean hemoglobin drop of $2.89 \mathrm{~g} / \mathrm{dL}$. Finally, there was a group of patients for which the clopidogrel was stopped 4 days before the surgery; while eight patients made up $15.7 \%$ of the cases. This did not fit into criteria set by the authors but it was interesting nonetheless to analyze. It revealed that the pre-operative hemoglobin ranged from $9.4-13.4 \mathrm{~g} / \mathrm{dL}$. The post-operative hemoglobin ranged from 7.9 - $11.9 \mathrm{~g} / \mathrm{dL}$. This group showed a mean hemoglobin drop of only $2.02 \mathrm{~g} / \mathrm{dL}$. In comparison, the control group with 40 patients was not on clopidogrel; and their mean hemoglobin drop was 2.54. All of these means were compared with one another using the one-way ANOVA as described in the result portion. It showed that there was no significant difference in the hemoglobin drop if clopidogrel was stopped 3 days prior to $\mathrm{CABG}$ as compared to 5 days. In fact there was no statistically significant difference in hemoglobin drop in any of the study groups when compared to each other. This is demonstrated in Table 9.

The other endpoint which we examined was the number of patients requiring $\mathrm{PRBC}$ after the $\mathrm{CABG}$ procedure. This is shown in Figure 4 in the result portion. It demonstrated the difference in the requirement for PRBC in all the groups post $\mathrm{CABG}$. The cumulative percent of patients requiring transfusions was $23 \%$. Out of all the patients who were taking clopidogrel, 12 of them required a blood transfusion, which is $24 \%$ of the patients. On the other hand, nine patients who were not on clopidogrel also required a blood transfusion, which is $22.5 \%$ of these patients. There was no significant difference in PRBC transfusion amongst the patients who were on clopidogrel as compared to those who were not on it. This is demonstrated in Table 10.

One other endpoint we looked into was MACE, which included ischemic cardiac events, cerebrovascular accident, or life-threatening arrhythmia. None of our patients were reported of having any of these complications. Two of our patients did develop tamponade after the procedure, one in the control and one in the case group.

\section{Limitations}

One of the main limitations of our study was that we only looked at short-term complications and bleeding and did not have enough data to analyze for long-term outcomes. Also we did not have exact details about how much blood was lost. The primary endpoints that we used were fall in hemoglobin, but theoretically there can be other non-hemorrhagic causes of fall in hemoglobin that could confound the primary outcome. These include excessive volume resuscitation and excessive blood draws. Finally our study was a small retrospective review, and larger prospective studies are needed to better elucidate the most optimal time to stop clopidogrel and to enable randomization of the study and control groups. However we made sure to match patients in two groups based on their demographics and comorbidities as mentioned in Table 1, this decreased our sample size but they were best matched for 
comparison. Moreover, the available data were insufficient to calculate Society of Thoracic Surgery Predicted Risk of Mortality (STSPROM) and that is the reason we did not analyze the mortality difference between the groups.

\section{Conclusions}

Our study concludes that there is no significant difference in hemoglobin drop and transfusion requirements whether clopidogrel is stopped 3 days versus 5 days before CABG procedure. Hence it is safe to allow patients to take clopidogrel up to at least 3 days prior to surgery. We further extrapolate that continuing clopidogrel decreases the risk of thrombosis and also has the added benefit of lower incidence of stroke, MI and cardiovascular death.

\section{Acknowledgments}

We want to thank Dr. Margot Boigon (program director) for providing research opportunities in the institute and for her support.

\section{Financial Disclosure or Funding}

None to declare.

\section{Conflict of Interest}

None to declare.

\section{Informed Consent}

Not applicable.

\section{Author Contributions}

WU drafted the manuscript and did revision, MAC shared the article idea and helped in data, HMA did data analysis, $\mathrm{AH}$ provided the resources and helped in IRB, SH did data gathering, MC did critical review and supervision.

\section{References}

1. Levy D, Larson MG, Vasan RS, Kannel WB. The progression from hypertension to congestive heart failure. ACC Current Journal Review. 1997;2(6):37.

2. Yusuf S, Zhao F, Mehta SR, Chrolavicius S, Tognoni G, Fox KK, Clopidogrel in Unstable Angina to Prevent Recurrent Events Trial Investigators. Effects of clopidogrel in addition to aspirin in patients with acute coronary syndromes without ST-segment elevation. N Engl J Med.
2001;345(7):494-502.

3. Jacob M, Smedira N, Blackstone E, Williams S, Cho L. Effect of timing of chronic preoperative aspirin discontinuation on morbidity and mortality in coronary artery bypass surgery. Circulation. 2011;123(6):577-583.

4. Ternstrom L, Radulovic V, Karlsson M, Baghaei F, Hyllner M, Bylock A, Hansson KM, et al. Plasma activity of individual coagulation factors, hemodilution and blood loss after cardiac surgery: a prospective observational study. Thromb Res. 2010;126(2):e128-133.

5. Head SJ, Milojevic M, Daemen J, Ahn JM, Boersma E, Christiansen EH, Domanski MJ, et al. Mortality after coronary artery bypass grafting versus percutaneous coronary intervention with stenting for coronary artery disease: a pooled analysis of individual patient data. Lancet. 2018;391(10124):939-948.

6. Anderson JL, Halperin JL, Albert NM, Bozkurt B, Brindis RG, Curtis LH, DeMets D, et al. Management of patients with peripheral artery disease (compilation of 2005 and 2011 ACCF/AHA guideline recommendations): a report of the American College of Cardiology Foundation/American Heart Association Task Force on Practice Guidelines. Circulation. 2013;127(13):1425-1443.

7. Hillis LD, Smith PK, Anderson JL, Bittl JA, Bridges CR, Byrne JG, Cigarroa JE, et al. 2011 ACCF/AHA guideline for coronary artery bypass graft surgery: executive summary: a report of the American College of Cardiology Foundation/American Heart Association Task Force on Practice Guidelines developed in collaboration with the American Association for Thoracic Surgery, Society of Cardiovascular Anesthesiologists, and Society of Thoracic Surgeons. Journal of the American College of Cardiology. 2011;58(24):2584-2614.

8. Yende S, Wunderink RG. Effect of clopidogrel on bleeding after coronary artery bypass surgery. Crit Care Med. 2001;29(12):2271-2275.

9. Hongo RH, Ley J, Dick SE, Yee RR. The effect of clopidogrel in combination with aspirin when given before coronary artery bypass grafting. J Am Coll Cardiol. 2002;40(2):231-237.

10. Buse JB, Ginsberg HN, Bakris GL, Clark NG, Costa F, Eckel R, Fonseca V, et al. Primary prevention of cardiovascular diseases in people with diabetes mellitus: a scientific statement from the American Heart Association and the American Diabetes Association. Circulation. 2007;115(1):114-126.

11. Fox KA, Mehta SR, Peters R, Zhao F, Lakkis N, Gersh BJ, Yusuf S, et al. Benefits and risks of the combination of clopidogrel and aspirin in patients undergoing surgical revascularization for non-ST-elevation acute coronary syndrome: the Clopidogrel in Unstable angina to prevent Recurrent ischemic Events (CURE) Trial. Circulation. 2004;110(10):1202-1208.

12. Yusuf S, Hawken S, Ounpuu S, Dans T, Avezum A, Lanas F, McQueen M, et al. Effect of potentially modifiable risk factors associated with myocardial infarction in 52 countries (the INTERHEART study): case-control study. Lancet. 2004;364(9438):937-952.

13. Lorell BH, Carabello BA. Left ventricular hypertrophy: 
pathogenesis, detection, and prognosis. Circulation. 2000;102(4):470-479.

14. Kannel WB. Blood pressure as a cardiovascular risk factor: prevention and treatment. JAMA. 1996;275(20):15711576.

15. Beckman JA, Creager MA, Libby P. Diabetes and atherosclerosis: epidemiology, pathophysiology, and management. JAMA. 2002;287(19):2570-2581.

16. Laing SP, Swerdlow AJ, Slater SD, Burden AC, Morris A, Waugh NR, Gatling W, et al. Mortality from heart disease in a cohort of 23,000 patients with insulin-treated diabetes. Diabetologia. 2003;46(6):760-765.

17. Paterson AD, Rutledge BN, Cleary PA, Lachin JM, Crow RS, Diabetes C, Complications Trial/Epidemiology of Diabetes Investigators, et al. The effect of intensive dia- betes treatment on resting heart rate in type 1 diabetes: the Diabetes Control and Complications Trial/Epidemiology of Diabetes Interventions and Complications study. Diabetes Care. 2007;30(8):2107-2112.

18. Haffner SM, Lehto S, Ronnemaa T, Pyorala K, Laakso M. Mortality from coronary heart disease in subjects with type 2 diabetes and in nondiabetic subjects with and without prior myocardial infarction. N Engl J Med. 1998;339(4):229-234.

19. Nelson RH. Hyperlipidemia as a risk factor for cardiovascular disease. Prim Care. 2013;40(1):195-211.

20. He J, Ogden LG, Bazzano LA, Vupputuri S, Loria C, Whelton PK. Risk factors for congestive heart failure in US men and women: NHANES I epidemiologic followup study. Arch Intern Med. 2001;161(7):996-1002. 